\title{
Moving on, Looking Back: Letters from Australia
}

\author{
David Rowe and Greg Noble \\ Institute for Culture and Society \\ Western Sydney University
}

\begin{abstract}
For almost two decades, Western Sydney University's Institute for Culture and Society (ICS) (and its predecessor unit, the Centre for Cultural Research (CCR)) has had a productive intellectual relationship with Tema Q/Department of Culture and Society at the Norrköping campus of Linköping University, where this journal is based. Higher degree research candidates and research academic staff from both universities have visited each other regularly, taking part in many academic conferences, symposia and seminars and contributing to the research culture at both sites, including joint research and publication. An important element of our cooperative activities has included significant involvement in the journal Culture Unbound, such as the special issue Mediatization, Mobility and New Methods of Knowledge Production edited by Tema Q's Martin Fredriksson and ICS's Alejandro Miranda (2017, Vol. 9, No. 3: https://cultureunbound.ep.liu.se/issue/view/11), and Culturalisation at an Australian-Swedish Crossroads edited by Tema Q's Johan Fornäs and Martin Fredriksson (2012, Vol. 4, No. 2: https://cultureunbound. ep.liu.se/issue/view/173).
\end{abstract}

Rowe, David and Noble, Greg: "Moving on, Looking Back: Letters from Australia", Culture Unbound, Volume 13, issue 2, 2021. Published by Linköping University Electronic Press: http://www.cultureunbound.ep.liu.se 


\section{Culture Unbound}

Journal of Current Cultural Research

This overlap of interests is manifest in each site's rationale. ICS, according to its mission:

researches transformations in culture and society in the context of contemporary global change. It champions collaborative engaged research in the humanities and social sciences for a globalizing digital age...

The Institute's research program speaks to these multidimensional problems and challenges. A key concern for the Institute is to address the increasingly problematic and uncertain status of knowledge in the contemporary world as a consequence of the increasing complexity of culture and society, including the rise of digital technologies.

(https://www.westernsydney.edu.au/ics/about_us)

This research agenda and approach is broadly shared with our Sweden-based colleagues, with whom we also collaborate in the production of new knowledge. A contingent of ICS staff and higher degree research candidates was meant to visit Sweden in 2020, but unfortunately the Covid-19 pandemic presented insuperable obstacles to travel. To maintain the research momentum, the Institute established a publication incentive scheme to encourage our research students to submit a research article to Culture Unbound. It must be emphasised that this involved a strict process of 'blind' peer review in which ICS staff played no active editorial or reviewer role. The four articles selected for publication in this sub-section are here entirely on their academic merit. They constitute a vivid snapshot of ICS's established, wide-ranging approach to cultural research and of the work of new generations of researchers who will carry it into the future.

Amrita Limbu's "Hearts in Australia, Souls in Nepal: Migration and Affective Intergenerational Aspirations" addresses the emotion-charged subject of young migrants who leave their families behind in the quest for global mobility. The current pandemic has given to this process a particular poignancy in obstructing the conventional flows of people around the world, including those trapped overseas and unable to attend funerals in their home countries (which are particularly elaborate in the case of Nepal). "The Careers of New Chinese Professional Women: Planning, Pathways and WeChat" by Yinghua Yu embraces comparable issues for migrants from East Asia. Again, she demonstrates the tensions created by looking, simultaneously, in two directions: towards origins in the People's Republic of China (PRC) and to new lives in Australia. Gender and occupation are shown to be crucial determining elements in this experience of relocation to a very different society. 


\section{Culture Unbound}

Gina Gatarin's "Surviving 'Car-diac Arrest': Towards Roads Where Many Modes Fit" is again Asia-focused, this time in the Philippines and its metropolis of Manila. She demonstrates that the minority of car owners obstructs the mobility of the majority and degrades the urban environment for all, making a persuasive case for an effective public transport system and for sustainable, active, self-directed movement around the city. It is a prescription applicable to many other congested urban sites in both hemispheres. Finally, an article mostly focused on Australia, "Decolonising the Museum? Dilemmas, Possibilities, Alternatives" by Vanessa Whittington, considers current pressures on institutions that benefitted from colonial violence to return cultural artefacts to their original owners, especially to Indigenous peoples. Her principal empirical focus is on Australian Aborigines and Torres Strait Islanders, but the questions that Whittington raises are highly pertinent elsewhere, such as in Scandinavia, which must negotiate its own histories of colonial dispossession of Sámi people.

This small, diverse set of articles is thematically linked by a common concern with various aspects of mobility, anchorage and displacement - spatial, social, historical and cultural - and their relationships to issues of power, equality and identity. The authors have found a sympathetic home in Culture Unbound in a sub-section that represents the latest chapter in a transcontinental scholarly relationship that continues to flourish and to defy time-space distantiation. 